\title{
REFLEXÕES ACERCA DO TURISMO COMO PRÁTICA PEDAGÓGICA NO ENSINO DE HISTÓRIA LOCAL
}

\section{ARTIGO ORIGINAL}

RAMOS, Érica Souza1 ${ }^{1}$ SANTOS, Rita de Cássia Grecco dos²

RAMOS, Érica Souza. SANTOS, Rita de Cássia Grecco dos. Reflexões acerca do turismo como prática pedagógica no ensino de história local. Revista Científica Multidisciplinar Núcleo do Conhecimento. Ano 06, Ed. 12, Vol. 11, pp. 147-166. Dezembro de 2021. ISSN: 2448-0959, Link de acesso: https://www.nucleodoconhecimento.com.br/educacao/turismo-como-pratica, DOI: 10.32749/nucleodoconhecimento.com.br/educacao/turismo-como-pratica

\section{RESUMO}

A partir do diálogo interdisciplinar entre a História e o Turismo emerge a presente pesquisa, que tem como foco o Ensino de História Local e sinaliza a escolha do Turismo como uma potente prática pedagógica no que tange aos processos de ensino e de aprendizagem relativos à História Local. Para tanto, esta pesquisa se caracteriza por ser um Estudo de Caso, realizado em uma escola Municipal de Ensino Fundamental no Balneário Cassino no município do Rio Grande/RS, tendo como sujeitos da pesquisa, professoras e alunos. Com 0 enfoque predominantemente qualitativo, partimos da seguinte questão: quais as possíveis consonâncias do Turismo como instrumento pedagógico no processo de aprendizagem da História Local? Assim, como objetivo geral, buscamos compreender as possíveis ressonâncias do Turismo na aprendizagem da História Local. Para tanto, nos debruçamos nos aportes teóricos no que se refere ao Ensino

\footnotetext{
${ }^{1}$ Mestre em História pelo Programa de Pós-Graduação em História da Universidade Federal do Rio Grande PPGH/FURG; Licenciada em Pedagogia, pela Universidade Federal do Rio Grande - FURG; Bacharel em Turismo, pela Universidade Federal do Rio Grande - FURG. ORCID: https://orcid.org/0000-0003-1189-1489

${ }^{2}$ Orientadora. Doutora em Educação, Socióloga, Pedagoga e Licenciada em História. ORCID:

https://orcid.org/0000-0002-6340-0920
}

RC: 104295

Disponível em: https://www.nucleodoconhecimento.com.br/educacao/turismo-comopratica 
de História e ao Turismo. Neste intento, esta pesquisa em seu percurso metodológico teve como uma das propostas planejar e realizar o Roteiro de Turístico Pedagógico: "Rio Grande: conhecendo a cidade aprendendo sua história", na Cidade do Rio Grande - RS. Foi realizado, também, a aplicação de um questionário com os alunos e a sua posterior análise. Desta maneira apresentamos algumas análises e reflexões à luz das narrativas dos alunos, tecidas em um encontro após a realização do Roteiro Turístico, a fim de compreender as consonâncias do Turismo no Ensino de História Local. Deste modo, percebemos que o Turismo ressignificou a forma de se posicionar e de perceber espaços e tempos diferentes, pois, por meio da experiência turística os alunos mobilizaram memórias, sentimentos e sentidos. Constatamos que os alunos, por meio das vivências no presente se estranharam e se identificaram com um passado, às vezes não tão distante, contribuindo para o entendimento da potente relação entre ensino de História Local e Turismo no desenvolvimento das práticas pedagógicas nos anos iniciais do Ensino Fundamental.

Palavras-chave: ensino de história, ensino de história local, práticas pedagógicas, turismo, formação de professores.

\section{INTRODUÇÃO}

O presente estudo está fundamentado a partir do diálogo interdisciplinar entre o Ensino de História e o Turismo, que tem como um de seus objetivos trazer elementos do Turismo para o Ensino de História Local. Desta maneira, esta pesquisa torna-se de relevância à medida em que o ensino da História Local como disciplina, por muito tempo ficou condicionada/restrita a grandes fatos e heróis, centrada em uma História Oficial, Política, carregada do ponto de vista eurocêntrico. Além disso, nos livros didáticos a História Local não está presente, o que faz com que o professor tenha que recorrer a outros suportes pedagógicos.

Para tanto, partindo de um enfoque predominantemente qualitativo, o presente estudo emerge a partir dos resultados do Estudo de Caso[3] acerca do Ensino de 
História Local no 4ํao ano dos Anos Iniciais do Ensino Fundamental, realizado em uma Escola Municipal de Ensino Fundamental, na cidade do Rio Grande/RS, que com o intento de compreender as contribuições do Turismo para o Ensino de História Local em seu percurso metodológico, teve como uma das propostas planejar e realizar o Roteiro de Turístico Pedagógico: "Rio Grande: conhecendo a cidade aprendendo sua história", com enfoque histórico-cultural na Cidade do Rio Grande, e após aplicação de um questionário com os alunos.

Cabe salientar que, a História Local é um conteúdo situado no âmbito escolar no $4^{\circ}$ ano do Ensino Fundamental, daí eis o momento que se pensa na formação do professor, pois neste período o profissional tem sua formação inicial em Pedagogia e não em História, o que nos levou a refletir sobre as práticas pedagógicas para o ensino de História Local. Nesse sentido, o Turismo é visto como uma potente prática pedagógica que pode vir a dar voz à História Local, que está próxima do presente vivido pelos professores e alunos, materializada nos espaços citadinos. Engendrando com os professores novas práticas pedagógicas para o ensino de História Local, em busca de um aprendizado prazeroso e lúdico, construindo um pertencimento histórico e também possibilitando o desenvolvimento de uma cultura turística nos envolvidos.

Para tanto, neste estudo realizamos em um primeiro momento breves reflexões teóricas acerca do Ensino de História Local e do Turismo. Em seguida, apresentamos os caminhos metodológicos da pesquisa e no terceiro momento apresentamos as reflexões em relação às consonâncias da atividade turística no Ensino de História Local, à luz das narrativas presentes no questionário contendo seis questões abertas, que foi aplicado com os alunos após a realização do Roteiro Turístico. 


\section{ENSINO DE HISTÓRIA E TURISMO: IMPORTANTES INTERSECÇÕES TEÓRICAS}

A História como campo disciplinar tem suas singularidades e seus campos de interesses que podem coincidir com objetos das demais Ciências Sociais e Humanas, estes que serão sempre historicizados. Nesta simbiose, observa-se a relevância da interdisciplinaridade, para Barros (2014, p. 30) "[...] ao se colocarem em contato interdisciplinar ou transdisciplinar, dois campos disciplinares podem enriquecer sensivelmente um ao outro nos seus próprios modos de ver as coisas e a si mesmos". A aplicação destes conhecimentos de forma partilhada permite a formação de uma visão holística aos pesquisadores e professores. Assim, observase que a busca pela interdisciplinaridade entre estes dois campos do conhecimento, a História e o Turismo, pode trazer elementos para as práticas pedagógicas no ensino de História Local.

Nesse sentido, a História enquanto ciência que permite o estudo das representações do passado e das suas projeções no presente e no futuro, alimenta a atividade turística. O saber histórico torna possível a compreensão de questões sociais, a partir de hipóteses sobre o passado, portanto:

O historiador, a partir de seu lugar social, sensibiliza-se por um objeto do passado e, através de fontes documentais de variada espécie, busca apreender esse objeto e construir, a partir de sua apreensão, uma interpretação desveladora de acontecimentos, de ações humanas, enfim, de culturas passadas (MENESES, 2006, p. 41).

O turismólogo vai se dedicar ao planejamento, interpretação e desenvolvimento do turismo, neste caso para o desenvolvimento do turismo cultural, o profissional, que

[...] tem sua base fundamental na interpretação de manifestações culturais que ele apreende, inventaria, documenta e transforma em atrativo para pessoas que buscam conhecer o outro e transformar este conhecimento em momento de abstração e fruição prazerosa. (MENESES, 2006, p. 42).

Os profissionais de Turismo muitas vezes se apoiam em interpretações históricas para constituir atrativos históricos e culturais, sendo assim, ambos profissionais

RC: 104295

Disponível em: https://www.nucleodoconhecimento.com.br/educacao/turismo-comopratica 
lidam com a interpretação de culturas, os historiadores as transformam em um texto interpretativo, e os turismólogos em um plano de exploração turística. Meneses salienta que, a utilização partilhada entre estes dois profissionais é de significativa importância, pois: "A produção de um serve a outro ou a interpretação pode ser feita de forma interdisciplinar" (MENESES, 2006, p. 42). Desta forma se o esforço de um profissional serve ao outro, por que não também servir ao ensino?

Destarte, o Turismo é compreendido nesta pesquisa como um instrumento facilitador nos processos de ensino e de aprendizagem por uma História Local mais prazerosa, lúdica e significativa, afinal: "O Turismo é um campo de práticas histórico-sociais que pressupõem o deslocamento dos sujeitos em tempos e espaços diferentes daqueles cotidianos" (GASTAL, 2007, p. 11).

Neste caso, partimos da concepção de que o turismo é um fenômeno social e prevê o deslocamento como sua parte fundamental, nestes deslocamentos viajamos em tempos e espaços diferentes dos que estamos acostumados a vivenciar. Neste sentido, não se trata da dimensão da distância percorrida e sim do processo de interação social, de estranhamento e identificação, e num tempo das coisas diferentes do que os rotineiros.

É nesse ponto que acreditamos que o Turismo se torna uma maneira pela qual o aluno pode referenciar seu olhar e conhecer seu espaço habitual, o bairro, o espaço citadino, ou seja, fazendo-se por compreender em seu "micro lugar" para se fazer entender posteriormente como parte de um universo maior: estado, país, nação, mundo. Que desta forma alunos(as) e professores(as) possam associar o conteúdo histórico à realidade do tempo presente a partir do Turismo, reverberando nos processos de ensino e de aprendizagem.

Por sua vez, a História Local no sistema de ensino é um conteúdo jovem no currículo escolar, talvez por conta disso careça de materiais e procedimentos metodológicos para que seja ensinado e apreendido em sala da aula de forma concisa. 
No final da década de 1990 o interesse pela História Local no ensino cresceu sob influência dos Parâmetros Curriculares Nacionais (PCN), elaborado pelo Ministério da Educação. A diretriz nacional curricular toma a História Local como um dos eixos temáticos dos conteúdos nos anos iniciais do ensino fundamental e como metodologia de ensino nos outros anos da escola básica (GERMINARI, 2014, p. 357).

Muitas vezes, o ensino de História do Brasil recai ao descuido de ser relacionado a uma matéria maçante, com referente acúmulo de informações e memorizações, o que torna o conhecimento superficial e desconexo com a realidade do aluno. Segundo Rocha (2014, p. 49): "A equação entre a necessidade de rigor e de boa comunicação desafia os professores na busca de estratégias para propiciar a aprendizagem da história".

Para tanto, Germinari (2014, p. 357) elucida que: “A opção pela História Local tem como proposta desenvolver a noção de pertencimento do aluno a um determinado grupo social e cultural, por meio, do estudo da diversidade dos modos de viver no presente e no passado da localidade". Neste sentido, é importante compreendermos as perspectivas para o ensino de História Local nos anos iniciais, que são atinentes às formulações do Plano Curricular Nacional - PCN, para este ciclo:

As formulações para o ensino de História a partir das séries (ou ciclos) iniciais do ensino fundamental sofrem variações, mas visam ultrapassar a limitação de uma disciplina apreendida com base nos feitos dos heróis e dos grandes personagens, apresentados em atividades cívicas e como figuras atemporais (BITTENCOURT, 2011, p. 112).

A História Local não deve seguir a dinâmica da História Nacional, em que para Barbosa (2016, p. 58): "A parte relevante desse conteúdo é apresentada sob a forma de culto aos sujeitos históricos, de glorificação dos atos individuais, portanto, uma história personalista que enfatiza determinadas datas, personalidades e fatos isolados de patriotismo". Neste sentido, a História Local possibilita a fuga da dinâmica da História personalista. Assim para Bittencourt:

A história local tem sido indicada como necessária para o ensino por possibilitar a compreensão do entorno do aluno, identificando o passado sempre presente nos vários espaços de convivência - escola, casa,

RC: 104295

Disponível em: https://www.nucleodoconhecimento.com.br/educacao/turismo-comopratica 
comunidade, trabalho e lazer -, e igualmente por situar os problemas significativos da história do presente (BARBOSA, 2016, p. 168).

Assim, compreendemos a importância do Ensino de História Local associado à história vivida, do tempo presente, possibilitando relacionar o que é apreendido em sala de aula ao cotidiano e às vivências presentes, contribuindo para a construção cognitiva do conhecimento crítico e o processo de formação do pensamento histórico. Deste modo, para que possamos compreender de que forma se dá o processo do conhecimento histórico para a transposição didática em sala de aula, além de ver o Turismo como um potente instrumento de ensino e de aprendizagem para a História Local, é de suma importância as análises de Rüsen (2015), em relação à matriz do pensamento histórico. Ele apresenta cinco fatores que compreendem o processo de formação do pensamento histórico:

O pensamento histórico é disparado pelas carências de orientação. Em seguida, ele transforma essas carências, no processo de sua satisfação mental, em perspectiva acerca da experiência do passado - em uma perspectiva de interpretação. Nesta perspectiva são inseridos, então, metodicamente, conteúdos experienciais concretos. O saber acerca do que aconteceu no passado, assim obtido, torna-se representação do passado em forma historiográfica (RÜSEN, 2015, p. 74).

Estes cinco caminhos cognitivos propostos por Rüsen (2015), nos levam ao saber histórico a partir das divergências temporais, estas que devem ser compreendidas e experienciadas na aprendizagem histórica. As diferenças temporais serão apreendidas a partir da carência de orientação, onde o "[...] conhecimento transforma as carências históricas de orientação em interesses do conhecimento" (RÜSEN, 2015, p. 75).

Nesse sentido, o autor não nega a crítica ao distanciamento que o pensamento histórico científico especializado toma em relação às carências de orientação e a vida prática dos sujeitos (professores e alunos). É neste ponto em que o Turismo e o Ensino de História começam a estabelecer uma linha tênue, à medida que a carência de orientação começa a ser trabalhada e a partir de indagações instigando aos educandos e gerando expectativas.

RC: 104295

Disponível em: https://www.nucleodoconhecimento.com.br/educacao/turismo-comopratica 
Dentre os cinco fatores, a narratividade é de suma importância, justamente para perceber a projeção cognitiva que o educando tem em relação a determinado conteúdo histórico. Doravante, lembra-se que a centralidade da narrativa não se dá pela sua totalidade factual ou por um modelo interpretativo, mas sim em poder relacionar passado, presente e futuro. A prática turística contribui neste caso para os educandos referenciarem o olhar para as representações do passado no presente. Portanto, a narrativa só se torna histórica quando relaciona presente, passado e futuro.

Sendo assim, as narrativas só podem ser compreendidas (quando apropriadas pelos professores) e elaboradas (educandos), quando fazem sentido para a orientação cultural "[...] da vida humana prática" (RÜSEN, 2015, p. 81), neste caso as narrativas só farão sentido se mantiverem uma relação intrínseca com a vida prática e a partir da tomada de consciência de sujeito histórico dos indivíduos, podendo se enxergar no processo histórico.

Foram feitas as reflexões à luz das palavras de Rüsen (2015), a fim de que pudéssemos perceber a mobilização cognitiva que perpassa a matriz do conhecimento histórico. Todavia, o Turismo aliado ao Ensino de História pode aparecer como uma forma de suprir as carências de orientação no que tange ao conhecer, gerando uma expectativa e possibilitando o vivenciar e a experiência. Sendo assim, o ensino e a aprendizagem histórica através da experiência alargam as possibilidades de percepção das mudanças e permanências entre o passado e o presente, facilitando a conexão do saber histórico e a vida prática dos sujeitos, tanto de professoras como de alunos.

Agora se torna pertinente adentrar na interpretação do questionário aplicado com os alunos após a realização do roteiro turístico, a fim de percebermos a possível ressonância do turismo na aprendizagem histórica. 


\section{CAMINHOS METODOLÓGICOS}

O fazer metodológico deste Estudo de Caso se justificou por ser interdisciplinar, tendo como premissa levantar dados acerca do Ensino de História Local nos Anos Iniciais de uma Escola Municipal de Ensino Fundamental do Balneário Cassino, na cidade do Rio Grande/RS, tendo como sujeitas (os) da pesquisa professoras e alunos do $4^{\circ}$ ano da escola.

Sinalizamos que esta pesquisa se caracteriza por ser um Estudo de Caso, quando volta o olhar para o estudo em profundidade em uma determinada escola, em uma turma e tendo como foco principal o Ensino de História Local. Assim, o estudo de caso "[...] é caracterizado pelo estudo profundo e exaustivo de um ou poucos objetos, de maneira a permitir o seu conhecimento amplo e detalhado" (GIL, 2014, p. $57)$.

Compreendendo que nos processos de ensino e de aprendizagem da história devemos ir além do que simplesmente recordar o passado e memorizá-lo, é que buscamos uma metodologia que propiciasse o rompimento do paradigma educacional tradicional, onde o aluno é a tabula rasa e o professor detentor do saber a ser proferido. Adotamos a abordagem da Aula Oficina (BARCA, 2004), uma proposta metodológica que se fez pertinente, ao passo que para além do rompimento de paradigmas educacionais tradicionais, essa metodologia proporcionou uma didática da história com maior flexibilidade, diálogo, utilização de materiais (fontes, imagens, vídeos e livros), a utilização do turismo como uma prática pedagógica, uma sequência na cognição histórica a partir das vivências e experiências, buscando a aproximação cognitiva do conteúdo com o vivido.

Neste intento, na Aula Oficina o aluno é o agente de sua formação, com ideias prévias e uma bagagem cultural e o professor, por sua vez, assume o papel de investigador social e organizador das atividades. Seguindo esta lógica, Barca (2004) nos elucida que o saber histórico na Aula Oficina é multifacetado, à medida em que possibilita a cognição em vários níveis: senso comum, ciência e epistemologia. 
Deste modo, a aprendizagem histórica, segundo Barca (2001), se dá em contextos concretos, sendo de suma necessidade que os conceitos façam sentido para quem vai aprendê-los, ainda mais quando falamos em História Local. Neste caso:

Existe uma multiplicidade de factores da cognição a ter em conta. As vivencias previas dos sujeitos e a natureza específica do conhecimento, o tipo de tarefas a desempenhar, as aptidões individuais são aspectos fundamentais para a progressão do conhecimento (BARCA, 2001, p. 20).

No que tange aos recursos e estratégias segundo Barca (2004), no modelo de Aula Oficina pode-se utilizar de múltiplos recursos para a intervenção e a avaliação, que se caracteriza por um momento de produção de material, testes e diálogos. Desta forma, Barca (2004), mostra que a projeção para uma aula de história deve levar em conta: a interpretação de fontes, a compreensão contextualizada de situações humanas e sociais em diferentes tempos e em diferentes espaços; e a comunicação no sentido de exprimir a sua interpretação e compreensão das experiências humanas ao longo do tempo sensibilidade e utilizando a diversidade dos meios de comunicação atualmente disponíveis.

Com base nesta concepção, a nossa proposta de Aula Oficina se desdobrou em três momentos distintos, mas complementares: a primeira ação foi a aula expositiva dialogada e a segunda se caracterizou pela realização do roteiro turístico histórico pedagógico. Sendo a terceira ação a atividade pós experiência do roteiro turístico, encontro caracterizado por uma conversa e aplicação do questionário.

Como o primeiro momento de intervenção, utilizamos a aula expositiva dialogada, intitulada "CIDADE DO RIO GRANDE: conversando sobre sua história", A aula expositiva dialogada teve como objetivo sensibilizar o olhar das (os) alunos e professoras para a História Local e para o Turismo. Utilizando de imagens antigas da cidade e atuais, fontes, vídeos e questionamentos. A aula expositiva em seu primeiro momento se caracterizou e teve como objetivo trazer marcos históricos e contextualizar a história da cidade, a partir de texto e imagens. No segundo momento o diálogo esteve orientado para as questões atinentes ao seu bairro e a sensibilização para o turismo e aos bens patrimoniais. 
O segundo momento da Aula Oficina foi a realização do roteiro Turístico Pedagógico "Rio Grande: conhecendo a cidade aprendendo sua história", cabe salientar que o roteiro foi planejado exclusivamente para a pesquisa, sendo assim, primeiramente teve seus pontos de interesses baseados no distanciamento do bairro de residência e a História Local. Para o planejamento deste roteiro foi necessária uma seleção cuidadosa dos atrativos turísticos a serem visitados, considerando o que foi apresentado na primeira parte da aula oficina e o conhecimento prévio dos alunos, bem como levando em conta o tempo de duração, que ocorreu em um dia letivo de aula no ano de 2018, ocupando o turno que teriam aula, das 13:30 às 17:30.

Um ponto de partida para seleção foi a manifestação de muitos alunos em relação a nunca terem ido a um museu, por conta disso foram inclusos no roteiro a visita em espaços museais e de memória (o Museu da Cidade do Rio Grande - MCRG; o Museu Oceanográfico Eliézer de C. Rios; a Fototeca Municipal Ricardo Giovannini; o Mercado Público Municipal e a Biblioteca Riograndense).

O roteiro então foi pensando como forma de que o turismo, uma vez planejado para fins pedagógicos, possa materializar a partir da experiência turística o saber histórico no que toca a história local, além de possibilitar a cognição a partir do estranhamento e identificação a partir do olhar diferenciado sobre os lugares citadinos que não são rotineiros. O roteiro então contou com a visita a espaços museais e de memória, contemplação da paisagem e a circulação a pé no centro histórico. Considerando a importância de vivenciar e sentir a história que está presente nas ruas da cidade, na praça, na paisagem, na circulação de pessoas, no tempo presente, materializada nas arquiteturas, monumentos e espaços públicos. É que acredito na possibilidade de um saber histórico multifacetado buscando a vivência e a compreensão contextualizada da trajetória humana em diferentes espaços e tempos.

Então o terceiro desdobramento da proposta de Aula Oficina, se caracterizou pelo encontro após o roteiro turístico, quando ocorreu um diálogo e reflexão sobre as ações anteriores: aula expositiva, o passeio turístico e a aplicação do questionário 
com os alunos da turma. Neste percurso, o questionário contemplou seis perguntas abertas, sendo respondido individualmente por cada um dos 19 alunos do $4^{\circ}$ ano envolvidos na atividade. A proposta de utilizar os questionários na atividade considerada de retorno teve como intuito perceber através das narrativas expressas nas respostas, a trama entre o vivido e a cognição da história local a partir da experiência turística a fim de compreender as consonâncias do turismo no processo de aprendizagem da História Local.

Para a interpretação dos dados, foi utilizado o suporte metodológico da análise de conteúdo. A análise de conteúdo, segundo Gil (2014), é desenvolvida em três fases, quais sejam, pré-análise, exploração do material e tratamento dos dados e interpretação: "Para interpretar os resultados, o pesquisador precisa ir além da leitura dos dados, com vistas a integrá-los num universo mais amplo em que poderão ter algum sentido" (GIL, 2014, p. 178).

Nesse sentido, após o tratamento adequado dos dados, foi realizada uma préanálise dos dados, "[...] é a fase de organização. Inicia-se geralmente com os primeiros contatos com os documentos (leitura flutuante)" (GIL, 2014, p. 152). $\mathrm{Na}$ sequência, a exploração do material aconteceu no que se refere às decisões tomadas na pré-análise. $\mathrm{Na}$ última etapa de análise, tem-se: "O tratamento dos dados, a inferência e a interpretação, por fim, objetivam tornar os dados válidos e significativos" (GIL, 2014, p. 153). É neste momento, que as interpretações dos dados e os fundamentos teóricos da pesquisa permitem a delimitação das problemáticas descobertas, a análise e reflexão. Assim, no presente artigo apresentamos as análises e reflexões no que se refere ao terceiro desdobramento da Aula Oficina, sob a luz das narrativas contidas no questionário aplicado com os alunos. 


\section{TURISTANDO PARA APREENDER: POSSÍVEIS RESSONÂNCIAS NO ENSINO DE HISTÓRIA LOCAL}

No reencontro com a turma, após a realização do passeio turístico, foi aplicado então um questionário com questões referentes à experiência a partir do roteiro turístico e, em seguida, foi proposto que o grupo elaborasse um postal, entendendo que:

Olhar a cidade com maior cuidado não é mais uma tarefa exclusiva dos turistas que a percorrem. Mesmo para os moradores das cidades, a sua complexidade coloca, cada vez mais, maiores desafios. Decifrá-los é fundamental para sobreviver e viver nas cidades com qualidade (GASTAL, 2007, p. 19).

A cidade passa a ser vista como espaço educativo de forma a oportunizar ao aluno um olhar cuidadoso para com o seu cotidiano, bem como construindo o conhecimento histórico por meio da própria cidade e as estruturas que a compõe. Nessa perspectiva, o Ensino de História na sala de aula deve estabelecer relações com o cotidiano dos alunos e professores, bem como de confrontar a experiência cultural dos alunos e professores com outras fontes de conhecimento histórico, em outras temporalidades e espaços. Assim, os Parâmetros Curriculares Nacionais PCNs apontam caminhos no que se refere ao Ensino de História para os anos iniciais:

Os conteúdos propostos estão constituídos, assim, a partir da história do cotidiano da criança (o seu tempo e o seu espaço), integrada a um contexto mais amplo, que inclui os contextos históricos. Os conteúdos foram escolhidos a partir do tempo presente no qual existem materialidades e mentalidades que denunciam a presença de outros tempos, outros modos de vida sobreviventes do passado, outros costumes e outras modalidades de organização social, que continuam de alguma forma, presentes na vida das pessoas e da coletividade. Os conteúdos foram escolhidos, ainda, a partir da idéia de que conhecer as muitas histórias, de outros tempos, relacionadas ao espaço em que vivem, e de outros espaços, possibilita aos alunos compreenderem a si mesmos e a vida coletiva de que fazem parte (BRASIL, 1997, p. 34).

Nesse sentido, percebemos que as interseções entre o Ensino de História e o Turismo aparecem no sentido de construir uma noção de patrimônio histórico-

RC: 104295

Disponível em: https://www.nucleodoconhecimento.com.br/educacao/turismo-comopratica 
cultural muito mais amplo. Pois, permitem o trabalho em espaços escolares e não escolares, com a História Local, o saber local e com diversas temporalidades que permeiam os objetos, para além dos espaços públicos atribuindo sentido para a sua coletividade. O Patrimônio Cultural também assumiu um caráter importante na formação da memória afetiva com os locais visitados.

Nesse viés, vejamos o que nos revelam os questionários, em relação à primeira pergunta: dos lugares que passamos o que você observou? Que teve como objetivo trazer à tona o que perpassou os olhares deles para os espaços que estavam sendo visitados. Assim, este material se tornou extremamente relevante para percebermos as possíveis ressonâncias do turismo para a aprendizagem da História Local, no que tange à transversalidade que a atividade turística incide sobre o olhar dos sujeitos.

Dos 19 alunos que responderam ao questionário, em 7 percebemos que observaram questões especificas em relação à conservação do Patrimônio Ambiental e Cultural, como presente na seguinte fala: "Que todos os lugares guardam histórias e relíquias. Mas fiquei triste que algumas pessoas não souberam conservar o nosso patrimônio, roubaram as estatuas, o chafariz estava sem água e tinha muito lixo espalhado pela Praça Xavier Ferreira" (Aluno do $4^{\circ}$ ano $\mathrm{A}$ ).

Nessa narrativa, o aluno mostrou um pensamento crítico em relação ao patrimônio, sobretudo, em relação às estruturas físicas, exaltando que ficou triste, demonstrando a preocupação com a preservação do patrimônio. Outra marca nas falas do grupo, diz respeito à questão particular do Chafariz da Praça Xavier Ferreira estar sem água, em um processo de manutenção no dia em que realizamos o roteiro, está questão esteve presente na fala de mais 4 alunos. Cabe destacar que, ele fez menção aos lugares que passamos como lugares que "guardam histórias e relíquias", se aproximando da ideia de lugares de memória proposta por Nora (1993), pois, segundo este autor estes espaços são:

[...] lugares, com efeito nos três sentidos da palavra, material, simbólico e funcional, simultaneamente, somente em graus diversos. Mesmo um lugar de aparência puramente material, como um depósito de arquivos, só é um local

RC: 104295

Disponível em: https://www.nucleodoconhecimento.com.br/educacao/turismo-comopratica 
de memória se a imaginação o investe de uma aura simbólica (NORA, 1993, p. 21).

Sendo assim, um objeto, uma rua, um monumento, uma porta, uma roupa, pode ser um local de memória se nele for investida imaginação e lembranças, numa articulação entre o simbólico, o material e o funcional, repercutindo em projeções de ações futuras que façam sentido na vida prática do aluno. Assim, o Turismo para além dessa relação, projetou uma cognição simbólica e preservacionista a partir do lazer no que tange os espaços visitados.

Então, no que tange ao estado de conservação do Patrimônio tanto Cultural como Ambiental, 4 alunos destacaram que passamos por monumentos pichados, 1 também destacou a presença de lixo no decorrer da Praça Xavier Ferreira, 3 relataram a insatisfação em relação a terem furtado estátuas da referida praça.

O cheiro, o aroma, foi uma questão que nos chamou atenção na fala dos alunos diante do que tinham observado; 2 alunos destacaram sobre o cheiro de pastel ao adentrar no Mercado Público e o "fedor" nas dependências da Biblioteca Riograndense: "Biblioteca pública. Era tam grande que nem tinha fedor de livros velhos. Mas na infantil tinha muito fedor, deve ser porque era muito piquena" (Aluno do $4^{\circ}$ ano A). Percebemos o quanto a visita a determinados locais marca a memória em relação aos sentidos dos sujeitos, suas sensações e emoções.

Neste caminho, a segunda pergunta do questionário foi relativa aos lugares que foram visitados e que eles não conheciam. O grupo teve por desconhecido o Museu da Cidade (10 alunos) e a Fototeca Municipal (9 alunos), apenas 1 aluno já conhecia todos os lugares visitados, e 3 alunos relataram que não conheciam nenhum dos lugares. Portanto, estes dados veem para reafirmar a importância social deste trabalho com o Turismo no que tange à oportunidade de conhecer espaços da sua própria cidade.

Desta maneira, em relação ao lugar como locus da atividade turística, Gastal (2007, p. 33) elucida que: "A visão da modernidade consagrou o lugar como o locus onde 
se concretizariam história e geografia e ao qual estariam atrelados cultura e identidade - pessoal e coletiva, local e nacional". Assim, o Turismo para o Ensino de História local, além de proporcionar experiências culturais diversificadas tem como esteira para este processo o local. Cabe salientar que, esse processo de conhecer foi tão marcante para a bagagem cultural dos alunos, que nos deixam expresso que:

Eu não conhecia a Fototeca e o Mercado Público, e agora que conheço vou convidar meus pais para irmos lá passear e olhar algumas fotos. Eu também não conhecia o museu da cidade e adorei visitá-lo (Aluno do $4^{\circ}$ ano A).

Eu na verdade não conhecia nenhum. Nunca avia visitado nenhum deles. Mas dizem que a primeira vez é a melhor! (Aluna do $4^{\circ}$ ano A).

Então, essa experiência vai para além do saber histórico, pois vai perpassar os muros da escola até sua família. Para tanto, fará parte do conhecimento prévio para as outras etapas da vida escolar e do repertório cultural dos alunos. Entendendo então, que a maioria estava visitando os espaços pela primeira vez, a terceira pergunta foi referente a qual momento tinham mais gostado. Nesta pergunta, os locais que a grande parte dos alunos gostaram foram o Museu Oceanográfico Eliézer de Carvalho Rios e o Museu Histórico da Cidade. Então, nesta pergunta o que tangencia são as preferências dos alunos, com destaque aos Museus, à medida que, para muitos, no Museu Histórico da Cidade havia elementos que não são familiares. Além disso, a possibilidade de ver os leões-marinhos e os pinguins nas dependências do Museu Oceanográfico, de certa forma, mexeu com o imaginário deles.

No caso do Museu Histórico da Cidade, ele exerceu uma de suas principais funções, contribuiu para o entendimento da História Local e a sua representação no momento presente. Como podemos perceber em outra narrativa que se torna pertinente em relação ao museu e o momento que mais gostaram, os alunos destacam que:

O momento que eu mais gostei foi no museu da cidade porque eu conheci mais a cidade e como antigamente como as pessoas se visitam, e etc (Aluna do $4^{\circ}$ ano $A$ ). 
Eu mais gostei de ir no museu da cidade, gostei da caixa registradora, das roupas que estavam lá e vi a arma que deu o $1^{\circ}$ tiro na guerra. Também gostei do vídeo sobre o navio Altair, que naufragou na praia do Cassino (Aluno do $4^{\circ}$ ano $\mathrm{A}$ ).

Assim, evidenciamos a representatividade que o acervo do museu tem em relação à construção mental e imaginária de como os eventos eram em tempos passados. Cabe salientar que, o Museu da Cidade trabalha com múltiplas linguagens, e a visita foi guiada por pessoas que trabalham no mesmo, para isso foi previamente agendada a visita. Deste modo, quando eles se referem ao vídeo, em um dado momento da visitação o grupo foi convidado a assistir uma produção do Grupo RBS, que fez parte do programa Curtas Gaúchos, intitulado "Os faróis e seus Guardiões", que versou sobre os Campos Neutrais, a Pirataria, os naufrágios, as guerras de fronteiras, a maré vermelha, os concheiros e os atoleiros. Esclarecemos esta questão em relação ao vídeo, porque em diversas falas atinentes à história da cidade apareceram referências aos piratas.

Agora, entramos nas questões com o foco mais tensionado para identificação, a ressignificação e a apreensão da História Local. Indicamos que a quarta pergunta do questionário não teve tanto o caráter de questionamento, mas que eles fizessem uma relação com a sua história e com o que tinham vivenciado durante o roteiro. $\mathrm{Na}$ tentativa de perceber se o que eles experienciaram em relação à História Local faz sentido para a vida prática deles.

Dos 19 alunos que responderam ao questionário, 9 conseguiram estabelecer uma relação de suas vivências e memórias junto com seus familiares em relação aos espaços percorridos durante o roteiro turístico. Destacamos as seguintes narrativas:

Eu comi pastel com minha mãe mercado público e busquei peixe com meu vô (Aluno do $4^{\circ}$ ano $\mathrm{A}$ ).

Sempre como eu vou no Mercado com a minha mãe eu e minha mãe comemos um picolé eu sempre como de uva e minha mãe como sempre de limão (Aluno do $4^{\circ}$ ano $\mathrm{A}$ ).

Eu já fui no mercado publico comprei ração para meu porquinho da índia o Ted, e foi lá que eu consegui o Ted (Aluna do $4^{\circ}$ ano A).

RC: 104295

Disponível em: https://www.nucleodoconhecimento.com.br/educacao/turismo-comopratica 
Desta maneira, os alunos fizeram uma aproximação afetiva e familiar das vivências anteriores nos espaços, mas efetivamente sobre a História Local e a sua não. As marcas do distanciamento do local de residência aos lugares visitados aparecem na fala de 2 alunos:

Isso foi muito diferente para mim já que eu moro no cassino eu já fui no museu oceanográfico eu gostei muito de ir em todos os lugares (Aluna do $4^{\circ}$ ano A)

Eu já fui com minha mãe no Museu Oceanográfico, mas eu não costumo ir com frequência porque eu moro no Cassino (Aluno do $4^{\circ}$ ano A).

Talvez por conta do distanciamento do bairro onde moram, tenha sido difícil estabelecer uma relação com a sua história, mas suas experiências os constituem como sujeitos históricos de seu tempo, desta maneira mesmo a ausência desta relação pode nos revelar o quanto é importante esse trabalho com o foco do Turismo, principalmente neste caso no que tange o Turismo Cidadão (GASTAL, 2007). Todavia, o sentido para a vida pratica é mobilizado operacionalmente, nesta questão eles não demonstraram a articulação entre o passado, o presente e o futuro em suas vivências narradas e sim suas memórias. Assim, nos 8 restantes eles não estabeleceram relação nenhuma com sua vida, apenas narraram a ordem de que foi realizado o roteiro turístico.

A quinta pergunta, "O que você sentiu ao caminhar pelo centro histórico?", nos possibilitou compreender como a atividade turística mobilizou as sensações e emoções deles em relação ao centro histórico e a história. Destarte, devemos destacar que estas emoções e sensações são desencadeadas por meio da apreciação estética dos lugares, desta maneira 14 alunos em suas narrativas destacaram sentimentos tais como: felicidade, animação, orgulho, tranquilidade, alegria, paz e raiva, como podemos apreciar:

Muita raiva por que o nosso centro histórico deixado estragando mas eu amo o nosso centro histórico! (Aluna do $4^{\circ}$ ano A).

Orgulho da nossa cidade por ela ser a primeira do estado do Rio Grande do Sul (Aluno do $4^{\circ}$ ano A).

RC: 104295

Disponível em: https://www.nucleodoconhecimento.com.br/educacao/turismo-comopratica 
Senti uma paz de espírito, uma calma a natureza do Centro Histórico tira a gente da agitação do dia a dia (Aluno do $4^{\circ}$ ano A).

Nestas falas podemos perceber o sentimento de pertença aflorado nos alunos diante da palavra orgulho, de amar o centro histórico, e raiva, pois este aluno em especial sente raiva por perceber a falta de consciência da população referente à preservação dos patrimônios. Além disso, quando um aluno destaca que o centro histórico "[...] tira a gente da agitação do dia a dia", nos aproximamos do que Gastal (2007), nos diz em relação ao turismo cidadão, que ao percorrer espaços e tempos diferentes está a experenciar tempos de viver diferentes do rotineiro. Assim, 5 alunos em suas respostas se aproximaram da apreensão histórica ao narrarem seus sentimentos:

Eu me senti uma menina contando a história de Rio Grande contando que a Biblioteca mais antiga é a biblioteca Riograndense que foi fundada em 1846 (Aluna do $4^{\circ}$ ano $\left.\mathrm{A}\right)$.

Eu senti muita emoção porque eu nunca fui nesse lugares que existiam antigamente! E agora eu já sei mais um pouco da nossa história! (Aluna do $4^{\circ}$ ano A).

Eu me senti viajando no passado do Rio Grande. E uma turista de antigamente! (Aluna do $4^{\circ}$ ano $\mathrm{A}$ ).

Eu já tinha caminhado varias vezes mas quando eu soube da História da cidade comecei a me interessar mais (Aluna do $4^{\circ}$ ano $\mathrm{A}$ ).

Eu senti que estava no passado! (Aluna do $4^{\circ}$ ano $\mathrm{A}$ ).

Percebemos nestas falas das alunas o quanto a atividade fez sentido para elas no que tange às carências de orientação (RÜSEN, 2015), e a relação passado, presente e futuro. A partir do momento em que uma aluna se sentiu "uma menina contando a história", e a outra que nunca tinha ido a esses lugares "de antigamente" e que agora sabe um pouco mais da "nossa" história, outra que já tinha passado por ali, mas quando soube mais sobre começou a se "interessar mais", podemos perceber que a partir do conhecimento adquirido elas projetaram ações futuras, representado, por exemplo, no interesse de saber mais, e ao usar o termo nossa para a história pensou no coletivo, não é a história da cidade e sim a nossa história. 
Deste modo, a utilização da palavra antigamente, e as sensações de estar no passado, viajando no passado, se sentir uma turista de antigamente, nos mostram que elas realizaram uma mobilização cognitiva no que tange ao tempo, ou seja, estavam experienciando com os olhos do tempo presente para o passado. A sexta pergunta teve como perspectiva que a turma construísse uma narrativa histórica sobre a história da cidade, como podemos perceber:

No século passado não existia carros e motos eles não tinham banheiro só tinha pinico. Não era tão moderno (Aluna do $4^{\circ}$ ano $\mathrm{A}$ ).

Há 2 anos muitas pessoas trabalhavam no estaleiro mas agora não tem mais estaleiro (Aluna do $4^{\circ}$ ano $\mathrm{A}$ )

Tinha muita pessoa que trabalhava no estaleiro mas hoje não existe mais o estaleiro. Isso é uma pena que não existe mais (Aluna do $4^{\circ}$ ano $\mathrm{A}$ ).

Eu lembro que à dois anos as pessoas trabalhavam muito no estaleiro e 0 fundador da cidade é o Brigadeiro José da Silva Paes (Aluna do 4a ano A).

Percebemos a proficiência histórica que coloca a história da cidade no tempo presente e passado, no contexto contemporâneo em um processo de rupturas e continuidades. Pois, um dos alunos destaca que "Não era tão moderno", sendo que, a concepção de moderno dele parte da tecnologia, dos carros, motos e o não ter banheiro, mas se pensarmos no século passado, o ter um pinico ou andar de trem poderia representar uma modernidade para aquele período histórico.

Outros destacam a questão da importância social do estaleiro e fazem um movimento temporal interessante, quando se referem ao estaleiro nos chama a atenção o recuo no tempo, narrativas foram construídas relacionando tempos e espaços diferentes. Como percebemos na seguinte narrativa: "O estaleiro parou de trabalhar a 2 anos. Numa época o chafariz fazia um grande papel porque antes eles precisavam pegar um balde para pegar água" (Aluno do $4^{\circ}$ ano $\mathrm{A}$ ). Ao passo que, parte de uma história mais próxima do presente vivido por ele, ele também utiliza o termo "numa época" para se referir a um passado longínquo. 
Estas 3 narrativas abarcam a pirataria, esta alusão aos piratas e aos naufrágios da nau Costa, a caracterização da cidade e a presença das águas em sua localização.

A cidade do Rio Grande é a primeira cidade do Rio Grande do Sul e é rodiada por águas (Aluno do $4^{\circ}$ ano $\mathrm{A}$ ).

Que os piratas assaltavam os navios de carga. Faziam fugueiras os piratas incalhavam e assaltavam (Aluno do $4^{\circ}$ ano A).

Rio Grande e a mais antiga do Rio Grande do Sul (RS). Existiu piratas em Rio Grande eles faziam fugueiras nas dunas de 3 metros tem até naufrágio na praia de Rio grande (Aluno do $4^{\circ}$ ano $\mathrm{A}$ ).

Nestas construções narrativas, destacamos a articulação com a Geografia, quando um dos alunos se refere a cidade estar rodeada por águas, pois sua posição geográfica Ihe confere o status de uma península em meio as lagoas e ao Oceano, portanto, a movimentação de embarcações, os constantes naufrágios e saques se dão em função desta posição.

Por último e não menos importante, destacamos uma narrativa que se aproximou de um discurso turístico: Rio Grande tem a maior biblioteca do estado, no bairro Cassino tem a maior praia do mundo, tem também vários pontos turísticos lindos como: As praças Xavier Ferreira, Tamandaré e Sete de Setembro (Aluno do $4^{\circ}$ ano A).

Notamos que nesta narrativa ocorre a predominância do discurso turístico em relação ao histórico. Neste percurso, a experiência turística levou os alunos à reconstrução do que havia sido vivido até aquele momento: "eu não conhecia", "eu já tinha passado por ali" e assim por diante.

Entendemos que o Turismo possibilitou a construção social dos sujeitos a partir do roteiro turístico, assim: "A experiência da viagem pode levar a pessoa a reconhecer características que foram manifestadas mais intensamente do que no tempo cotidiano, e a relação dialética entre expectativas e resultados" (SANTOS, 2001, p. 208). Desta maneira percebemos que grade parte do grupo se apropriou e compreendeu o passado por meio das evidências históricas presentes nos lugares

RC: 104295

Disponível em: https://www.nucleodoconhecimento.com.br/educacao/turismo-comopratica 
onde passamos. Numa construção mental, os alunos se apropriaram do passado a partir dos indícios documentais, e da experiência cultural a partir da realização do roteiro turístico proposto.

\section{CONSIDERAÇÕES FINAIS}

Neste percurso, a partir da experiência turística, os alunos ressignificaram o olhar para a sua cidade, numa perspectiva cultural da dialética do conhecer e não conhecer, do cotidiano e do distante, do presente e do passado. A partir deste "novo olhar", momento da realização do roteiro turístico, um olhar formado a partir de um novo sujeito que emerge o aluno-turista, percebemos aflorar sentimentos e emoções que antes não havia presenciado, até mesmo ao percorrer os mesmos espaços sem o olhar turístico.

Desta maneira, os alunos acionaram a consciência histórica, mas enfaticamente consideramos que a mobilização a partir do roteiro despertou o pertencimento histórico, pois, em suas narrativas conseguiram fazer um deslocamento temporal a partir das vivências do presente, estranharam e se identificaram com o passado, às vezes não tão distante.

Concluímos que, os patrimônios culturais foram os principais vestígios do passado que levaram aos alunos a mobilizar seus sentidos, o desejo de conhecer, saber mais, de rememorar o passado e preservar. Mas, o Turismo a partir da proposta inicial desta pesquisa teve repercussão em relação ao repertório cultural dos alunos, do modo a se posicionar e perceber os diferentes espaços e tempos em que passamos.

Contudo gostaríamos de destacar a importância de se pensar o Turismo para/na formação de professores, tanto a inicial como a continuada, visto que a prática turística pode sensibilizar os sujeitos à compreensão das concepções de lugar, espaço e tempo. Valorizar o turismo na formação de professores, atualmente, torna- 
se necessário, pois tais conhecimentos podem ser revertidos aos alunos e se transformar em uma potência de ensino interdisciplinar.

Não devemos lançar mão da concepção do Turismo como mera atividade econômica, mas percebê-lo como um fenômeno social e que, aliado à educação, permite experiências educacionais significativas e a formação de sujeitos críticos e ativos. Convém destacar que o Turismo nas Escolas também desenvolve a sensibilização turística dos alunos, se constituindo como uma via de mão dupla, neste viés almejamos que o Turismo e a Educação estreitem os laços e quem sabe possa emergir nos planos curriculares das Escolas Municipais de Ensino Fundamental.

\section{REFERÊNCIAS}

BARBOSA, Vilma de Lurdes. Ensino de história local: redescobrindo sentidos. In: SEACULUM - Revista de História. p. 57-85. João Pessoa, jul./dez. 2016. Disponível em:<http://www.biblionline.ufpb.br/ojs/index.php/srh/article/viewFile/11357/6471> Acesso em: 06/06/2019.

BARCA, Isabel. Aula Oficina: do Projeto à Avaliação. In: Para uma educação de qualidade: Atas da Quarta Jornada de Educação Histórica. Braga, Centro de Investigação em Educação (CIED)/ Instituto de Educação e Psicologia, Universidade do Minho, $2004 . \quad$ Disponível em: <http://sefarditas.net.br/ava/aula_oficina/isabel_barca1.pdf> Acesso em: 02/05/2018. . Educação Histórica como área de investigação. In: Revista da Faculdade de Letras HISÓRIA. Porto: III série, v. 2, 2001. Disponível em:<https://ler.letras.up.pt/uploads/ficheiros/2305.pdf> Acesso em: 02/05/2018.

BARROS, José D' Assunção. Teoria da História. 5 ed. Petrópolis: Vozes, 2014. 
BITTENCOURT, Circe Maria Fernandes. Ensino de história: fundamentos e métodos. 4 ed. São Paulo: Cortez, 2011.

BRASIL. Secretaria de Educação Fundamental. Parâmetros curriculares nacionais: história, geografia. Brasília: MEC/SEF, 1997.

GASTAL, Susana. Turista cidadão: uma contribuição ao estudo da cidadania no Brasil. 2006. Disponível em: <www.intercom.org.br/papers/nacionais/2006/ resumos/R0338-2.pdf.> Acesso em: 09/09/2017.

- Nomadismo e Turismo: Viagem como Vida no Espaço. In: Análises regionais e globais do turismo brasileiro. Ed. Luiz Godoi Trigo; Co Ed. Alexandre Panosso Netto; Mariana Aldrigui Carvalho; Paulo dos Santos Pires. São Paulo: Roca, 2005.

GERMINARI, Geyso D. O ensino de história local e a formação da consciência histórica de alunos do $6^{\circ}$ ano do ensino fundamental: uma experiência com a unidade temática investigativa. In: XIV ENCONTRO REGIONAL DE HISTÓRIA 1964 - 2014: 50 anos do golpe militar no Brasil. 7 a 10 de out. de 2014. Disponível em: < http://www.erh2014.pr.anpuh.org/anais/2014/335.pdf> Acesso em: 8/06/2019.

GIL, Antonio Carlos. Métodos e técnicas de pesquisa social. São Paulo: Atlas, 2014.

MENESES, José Newton Coelho. História e Turismo cultural. Belo Horizonte: Autêntica, 2006.

NORA, Pierre. Entre memória e história. A problemática dos lugares. Projeto História. Revista do Programa de Estudos Pós-Graduados em História do Departamento de História. São Paulo: 1993. n. 10 
ROCHA, Helenice. A presença do passado na aula de História. In: MAGALHÃES, Marcelo et al (orgs). Ensino de História: usos do passado, memória e mídia. Rio de Janeiro: FGV, 2014.

SANTOS, Ágatha Alexandre; BANDUCCI JR, Álvaro; BARRETTO, Margarita (orgs.). Construção social da pessoa no turismo: um estudo de caso. In: Turismo e identidade local: Uma visão antropológica. Campinas: Papirus, 2001.

\section{APÊNDICE - REFERÊNCIA DE NOTA DE RODAPÉ}

3. Este estudo é tributário da pesquisa intitulada "Turismo como Prática Pedagógica no Ensino de História Local nos Anos Iniciais do Ensino Fundamental: um estudo de caso em uma escola do Rio Grande/RS", apresentada ao Programa de PósGraduação em História da Universidade Federal do Rio Grande - PPGH/FURG, no ano de 2019.

Enviado: Agosto, 2021.

Aprovado: Dezembro, 2021. 